\title{
Standard for the Exchange of Nonclinical Data Implementation Guide Version 3.1
}

National Cancer Institute

\section{Source}

National Cancer Institute. Standard for the Exchange of Nonclinical Data Implementation

Guide Version 3.1. NCI Thesaurus. Code C120925.

The 3.1 version of the standard for exchange of nonclinical data (SEND) implementation guide. 